\title{
GYNODIOECY IN PLANTAGO LANCEOLATA L I. POLYMORPHISM FOR PLASMON TYPE*
}

\author{
J. M. M. VAN DAMME $†$ and W. VAN DELDEN \\ Department of Genetics, University of Groningen, Biology Centre, Kerklaan 30, 9751 \\ NN Haren (The Netherlands)
}

Received 30.vi.82

\begin{abstract}
SUMMARY
Studies of the morphological polymorphism for the expression of male sterility in the gynodioecious species Plantago lanceolata revealed two separate series of stamen forms from sterile to fertile. The first type of complete male sterility (MS1) shows a disturbed development of the stamens, which are strongly reduced in size. The second type (MS2) has stamens which are petaloid. In the latter type the corolla and sometimes the pistil are also affected. Evidence is presented that these differences in expression of male sterility are cytoplasmically determined. The plasmon types are designated $R$ and $P$ respectively. In each plasmon type a series of intermediate sex forms occurs. Field counts showed that these intermediates are a non-negligible proportion of most populations. On the average MS1 reaches higher frequencies than MS2. Twenty two out of 27 populations appeared to be polymorphic for plasmon type. The remaining five populations are probably fixed for plasmon $P$ and their distribution over the habitats studied suggests that the fitnesses of the different sex genotypes depend on environmental conditions.
\end{abstract}

\section{INTRODUCTION}

THE presence of both hermaphrodite and male sterile plants in populations is referred to as gynodioecy. Extensive theoretical analyses of this breeding system have been undertaken in the past decade; this is primarily due to the fact that selection is involved in the maintenance of male sterility. Lewis (1941) was the first to state the problem in quantitative terms and he made clear that the disadvantage of the male sterile phenotype depends upon the mode of inheritance of male sterility. Later studies centered mostly upon mechanisms for maintenance within the framework set by Lewis i.e., in cases with either nuclear or cytoplasmic inheritance. Relatively few authors tried to describe the conditions for maintenance of male steriles in the more general case of nuclear-cytoplasmic inheritance.

Recently it has been argued by Ross (1978) that there are two classes of gynodioecy, an unstable type which would readily evolve towards (sub)dioecy, and a stable type. In the former, male sterility is inherited by a nuclear gene and (sub)dioecy develops after the introduction of (partial) female sterility genes which become linked to the male sterility gene. This possibility has been explored theoretically by Ross and Weir (1976), Ross (1978) and Charlesworth and Charlesworth (1978a). Evidence in support of this has been based on comparisons of female fertility between species

\footnotetext{
* Grassland Species Research Group Publication No. 54.

+ Present address: Institute of Ecological Research, Duinzoom 20a , 3233 EG Oostvoorne, The Netherlands.
} 
in several plant genera like Fuchsia (Arroyo and Raven, 1975) and in apioid Umbelliferae (Webb, 1979). The stable type of gynodioecy would result from its being prevented from evolving towards dioecy. The mechanism is considered to involve cytoplasmic inheritance of male sterility because linkage between female sterility genes and the plasmon factor cannot occur (Ross, 1978; Charlesworth and Charlesworth, 1978a).

A number of models have been proposed for the maintenance of male sterility with nuclear-cytoplasmic inheritance. Most models do not permit equilibria in which variation for both nuclear genes and plasmon type is present (joint equilibria): either no fitness difference was assumed (Watson and Caspari, 1960, Caspari et al., 1966; Costantino, 1971) or only differences between sex phenotypes, and not between genotypes having the same sex phenotype (Charlesworth and Ganders, 1979). The first example of a joint equilibrium came from Valdeyron et al. (1970). More thorough treatments of the model were given by Charlesworth (1981) and Delannay et al. (1981). In both studies it appeared that for stable joint polymorphism, fitness differences within sex phenotypes are required that are associated with the genetic factors causing male sterility.

Experimental data that can be used to discriminate between these different models, are scarce. What is needed are data on the genetics of male sterility, spatial distribution of the genetical factors and fitness estimates as a function of sex genotype rather than of sex phenotype. This paper is the first in a series on the maintenance of gynodioecy in which these aspects will be dealt with on the basis of a case study of Plantago lanceolata. Here we will be mainly concerned with the involvement of cytoplasm in the determination of male sterility and the distribution of two plasmon types between populations.

It is generally accepted that genetic information from both cytoplasm and nucleus is necessary for stamen development (Grun, 1976). This is the result of numerous studies on the inheritance of male sterility, most of which have been conducted on agricultural species (for a review see Edwardson, 1970). Although most data on gynodioecious species do not permit definite conclusions, the overall picture is the same (see Charlesworth, 1981). For the few species in which only nuclear inheritance has been claimed, such as in Cortaderia richardii (Connor, 1973), KheyrPour (1981) has pointed out that an explanation can be found in the restriction of the number of initial parents (potentially different plasmon types) and in the absence of critical crosses. Similarly there is a difference between demonstrating that male sterility in a particular species is determined by nuclear-cytoplasmic inheritance and that a joint polymorphism exists in populations of that species unless the genetic study has been carried out with plants from a single population (for example see Ganders, 1978). As yet, no evidence has been presented that a joint polymorphism is common in any gynodioecious species, although the suggestion has been made for Origanum vulgare that numerous plasmon types exist within populations (Kheyr-Pour, 1980, 1981). In the present study close observations on the morphology of male sterility in Plantago lanceolata have provided us with a marker for plasmon type, enabling us to determine in a simple way whether or not such a polymorphism exists. It turns out-and this is generally valid-that the problem is to show that populations are uniform for plasmon type rather than the opposite. 
The aim of the paper is threefold. Firstly the morphological polymorphism for male sterility, previously described by numerous authors, will be reexamined. It will be shown that there are two male sterility types. Then evidence will be presented for cytoplasmic determination of flower phenotype in male sterile plants. Finally the distribution of sex phenotypes will be studied in natural populations in relation to environmental factors. It will be made clear that the majority of the populations studied is polymorphic for plasmon type and that there are differences in distribution between the two sterility types.

\section{MATERIALS AND METHODS}

The male parts of flowering spikes can be assessed visually with the naked eye after some training, but in cases of doubt, spikes were collected and examined under a binocular microscope. In crossing experiments at least five spikes per plant were scored for male sex, representing a total of several hundred flowers. In the field all flowering spikes per plant, usually less than five, were taken. Pollen fertility was inferred from stainability of pollen grain contents (Alexander, 1969). Counts were made under a light microscope (approximately 350 grains per count). Staining was in fact unnecessary because empty grains are much smaller than normal ones (18 versus $29 \mu \mathrm{m}$ ) with hardly any overlap. The species is protogynous and for crosses young spikes were bagged before female flowering. The presence of a self-incompatibility system (Ross, 1973) allows reciprocal crossing between hermaphrodites by simply bagging together spikes of two plants. Seeds were germinated in petri dishes and plants grown in the experimental garden. Germination and subsequent survival until flowering was 93 per cent. Plants that were used for crosses came from three different populations: Wd in Goeree in the south-west, Gr near Groningen in the north and $\mathrm{He}$ near Arnhem in the east of The Netherlands. Field counts were made in these and other populations in the same regions up to a total of 25 (listed in table 5). In addition two populations, Lu and Lx, in Luxemburg were examined. Within each population a homogeneous patch was taken, varying in size from $200-500 \mathrm{~m}^{2}$, which was sampled systematically. Counts were made in June, the peak flowering period, in 1980 and 1981. Soil samples were all taken in June 1981 at a depth of seven $\mathrm{cm}$. Moisture content was calculated after drying the sample for 24 hours at $70^{\circ} \mathrm{C}$. Analyses of $p \mathrm{H}$, organic matter-, nitrogen- and phosphorus content were performed according to methods described in Troelstra et al. (1981).

\section{RESUlts}

\section{(i) Morphological polymorphism for male sterility}

Hermaphrodite flowers of Plantago lanceolata have four stamens with cylindrical filaments and white anthers, containing yellow pollen and dehiscing by longitudinal slits. The filaments start from the receptacle and run along the inside of the corolla tube, alternatingly with four corolla lobes. Before anthesis they are folded inversely U-shaped inside the tube, but at exertion they unfold, lifting the anthers out into the open (fig. 1a). Close observations reveal two different male sterility types in Plantago 


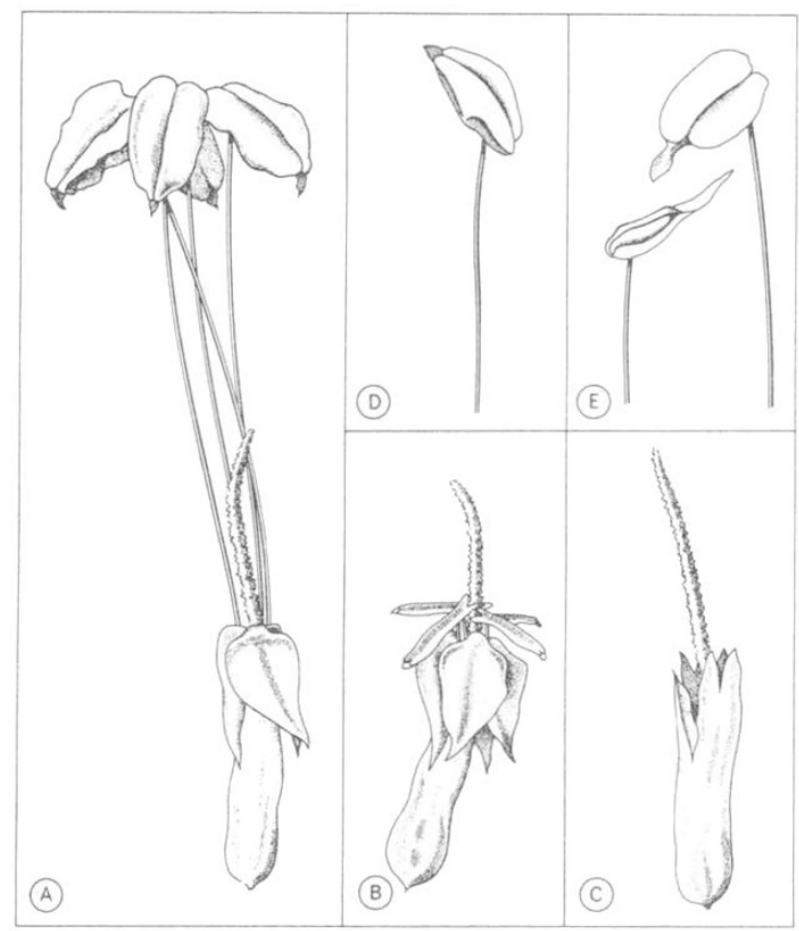

FIG. 1.-Flower and anther types in Plantago lanceolata: (A) flower of H plant, (B) flower of MS1 plant, (C) flower of MS2 plant, (D) typical anther of IN1 series (intermediate-1), (E) typical anthers of IN2 series (intermediate- $2 a$ and $-2 b$ respectively).

lanceolata. These types differ in the developmental stage at which deviant development is initiated, and consequently in morphology.

In the first type of male steriles, designated MS1, flower development is normal up to the stage of anther differentiation, resulting in a flower in which only the stamens are affected (fig. 1b). Filaments are short and anthers, protruding just outside the corolla tube, are yellowish-green when young but rapidly turn brown. Pollensacs can be discerned but they do not contain any pollen.

Differences in flower development between the second type of male steriles (MS2) and hermaphrodites start at an earlier stage. Not only stamens but also the corolla and sometimes even the pistil are affected. In the most extreme form stamens are completely absent. Instead there is an irregular eight-lobed corolla with a short tube and calyx-pigmentation (Fig. 1c). The corolla is rigid: it never expands ("closed flowering", Correns, 1908; Stout, 1919) nor does it grow with the maturing fruit to keep it sheathed, in contrast to other flower types. Sometimes the style cannot leave the narrow corolla and gets coiled up inside, thereby possibly lowering the chance of pollination. Pistils of these flowers occasionally have three-seeded capsules while two seeds are normal. Less extreme MS2 flowers can have eight-lobed corollas of normal length and pigmentation ("double flowering", Correns, 1908) or a normal corolla with stamens represented by strips of tissue of various lengths and shapes without any sign of anther differentiation. 
In each sterility type a continuous series of intermediate plants occurs (IN1, IN2). These partially male sterile plants often bear mixtures of sterile, fertile and intermediate anthers. Some typical intermediate anthers of both series are shown in figs $1 \mathrm{~d}$ and $1 \mathrm{e}$. They can be distinguished from each other by the sterile tip at the apex. In the IN2 series the tip is always larger than in hermaphrodites while it is normal in length and form in the IN1 series. The intermediate anther classes as shown in figs $1 \mathrm{~d}$ and $1 \mathrm{e}$ were examined for pollen fertility. Anthers of the two series were collected under different breeding conditions. In each series anthers from hermaphroditic sibs of intermediate plants were taken as controls. The results are presented in table 1. Comparisons should only be made within each series because male fertility is known to be sensitive to environmental conditions (Frankel and Galun, 1977). In both series pollen fertility decreases from fertile towards sterile anther forms while variation between anthers increases considerably.

Thus we distinguish five sex phenotypes: MS1, IN1, MS2, IN2 and hermaphrodites which will be designated $\mathrm{H}$.

\section{TABLE 1}

Percentage stainable pollen as a function of anther type. Average $(\overline{\mathrm{x}})$, range and coefficient of variation $(C . V$.$) are given together with the number of anthers examined. Type 1$ anthers were collected in the greenhouse, type 2 anthers in the experimental garden. Intermediate anther types correspond with figures $1 d$ and $1 e$

$\begin{array}{lcrcc}\quad & \bar{x} & \text { Range } & \text { C.V. } & \text { Sample size } \\ \text { Anther type } & 52 \cdot 6 & 7-89 . & 0.57 & 12 \\ \text { intermediate-1 } & 86 \cdot 5 & 58-97 & 0 \cdot 14 & 11 \\ \text { hermaphrodite-1 } & 46 \cdot 2 & 1-94 & 0.83 & 10 \\ \text { intermediate-2a } & 90 \cdot 2 & 66-97 & 0.13 & 8 \\ \text { intermediate-2b } & 94 \cdot 2 & 82-99 & 0.05 & 14\end{array}$

(ii) Cytoplasmic determination

An extensive crossing programme was set up in order to study the genetics of male sterility. Ross (1967) has suggested that inheritance of male sterility is nuclear-cytoplasmic but only the involvement of nuclear genes was actually shown (Ross, 1969). In this paper we focus on the genetic control of male sterile morphology. Inheritance of this characteristic appears to be exclusively maternal.

In tables 2, 3 and 4 a summary is presented of 133 crosses with on the average 80 plants per progeny, giving a total of 10,647 plants, of which two thirds had some degree of male sterility. Since there is no difference between complete and partial male sterility with respect to morphological type these sex phenotypes will be taken together, when appropriate and they will be referred to in the text as type 1 or 2 steriles. The first evidence for extrachromosomal inheritance is that the two male sterility types did not segregate in any of the progenies, while segregation of male steriles and intermediates of the same type was common.

Table 2 gives a summary of a crossing experiment with various sex phenotypes. All twelve original parents came from one population (Wd). The second generation consisted mainly of backcrosses (BC1) on the paternal parent. In total $25 \mathrm{MS} 1,9 \mathrm{MS} 2$ and $15 \mathrm{H}$ plants were involved 


\section{TABLE 2}

Summary of a crossing programme with plants from the Wd population. Crosses are grouped according to parental phenotypes. $\mathrm{H} 1$ and $\mathrm{H} 2$ are hermaphrodites that are able to segregate type 1 and type 2 steriles respectively when used as females. For further details see text

\begin{tabular}{|c|c|c|c|c|c|}
\hline $\begin{array}{c}\text { Parental } \\
\text { phenotypes }\end{array}$ & \multicolumn{2}{|c|}{$\begin{array}{l}\text { No. of } \\
\text { crosses } \\
\text { in } \\
\text { generation }\end{array}$} & \multicolumn{3}{|c|}{ No. of offspring } \\
\hline$q \delta$ & P & $\mathrm{BC} 1$ & MS1 + IN1 & $\mathrm{MS} 2+\mathrm{IN} 2$ & $\mathbf{H}$ \\
\hline $\mathrm{MS} 1 \times \mathrm{H} 1$ & 12 & 13 & 1360 & 0 & 766 \\
\hline $\mathrm{MS} 1 \times \mathrm{H} 2$ & 8 & 14 & 1715 & 0 & 50 \\
\hline $\mathrm{MS} 2 \times \mathrm{H} 1$ & 4 & 5 & 0 & 508 & 256 \\
\hline $\mathrm{MS} 2 \times \mathrm{H} 2$ & 6 & 5 & 0 & 554 & 357 \\
\hline $\mathrm{H} 1 \times \mathrm{H} 1$ & 6 & 4 & 271 & 0 & 303 \\
\hline $\mathrm{H} 1 \times \mathrm{H} 2$ & 7 & 4 & 504 & 0 & 443 \\
\hline $\mathrm{H} 2 \times \mathrm{H} 1$ & 7 & 4 & 0 & 370 & 566 \\
\hline $\mathrm{H} 2 \times \mathrm{H} 2$ & 6 & 4 & 0 & 311 & 301 \\
\hline
\end{tabular}

which each served on average $2 \cdot 2$ times as a female parent. In all crosses where male steriles were used as female parents, there was a perfect correspondence between the sterility type of the female parent and of the male steriles in her offspring, irrespective of the male parent. Hermaphrodites behaved in the same way. When used as a female parent, they segregated only one type of male sterile, either type 1 or type 2 and they are accordingly designated $\mathrm{H} 1$ and $\mathrm{H} 2$. The two types of hermaphrodites are indistinguishable by their own anther morphology but they pass on a particular morphology to the male steriles in their offspring. Of the $15 \mathrm{H}$ parents, 8 turned out to be $\mathrm{H} 1$ and $7 \mathrm{H} 2$. Table 2 gives the result of eleven different reciprocal crosses between $\mathrm{H} 1$ and $\mathrm{H} 2$ plants. The results are in agreement with maternal inheritance of male sterile morphology. Not included in the table are data showing that those hermaphrodites which were known to be of a particular type by descendance, segregated that same type in their progeny according to expectation.

Further evidence for maternal inheritance was obtained by reciprocal crosses between hermaphrodites from three different populations (table 3 ). The two plants from the Wd population, Wd-a and Wd-b, were respectively $\mathrm{H} 1$ and $\mathrm{H} 2$ and were also used in the previous experiment. The other plants were a $\mathrm{H} 2$ plant from the He population and a $\mathrm{H} 1$ plant from the Gr population. Distances between the populations are at least 100 kilometers. The results in table 3 show that maternal inheritance of male sterile morphology is not a peculiarity of only one population.

It is known that simple reciprocal crosses are not sufficient to show true maternal inheritance. They leave the possibility of a late acting gene influencing the progeny (cf. Grun, 1976). Evidence against this possibility already existed from the Wd experiment which was continued for two generations (table 2), but to rule it out completely a reciprocal backcross series was started with the hermaphrodites $\mathrm{Gr}-\mathrm{a}$ and $\mathrm{He}-\mathrm{a}$ as parents. In each generation a number of male steriles were backcrossed to the male parent. The nature of the self-incompatibility system (Ross, 1973) caused half of the crosses for the backcross generations 2 and 3 to be incompatible (12 out of 30 ). The results of the first three backcross generations are 
TABLE 3

Results from reciprocal crosses between hermaphrodites from three different populations: $W d$, $\mathrm{He}$ and $\mathrm{Gr}$. The Wd-a and Gr-a plant are H1, the Wd-b and He-a plant $\mathrm{H} 2$

\begin{tabular}{ccccccrr} 
Cross & \multicolumn{4}{c}{$\begin{array}{c}\text { Reciprocal } \\
\text { cross }\end{array}$} & \multicolumn{2}{c}{ No. of offspring } \\
& MS1+ IN1 & MS2+IN2 & H & & MS1 + IN1 & MS2 + IN2 & H \\
Wd-a $\times$ Gr-a & 45 & 0 & 14 & Gr-a $\times$ Wd-a & 36 & 0 & 18 \\
Wd-b $\times$ He-a & 0 & 26 & 24 & He-a $\times$ Wd-b & 0 & 17 & 36 \\
Wd-a $\times$ He-a & 17 & 0 & 35 & He-a $\times$ Wd-a & 0 & 0 & 53 \\
Gr-a $\times$ Wd-b & 37 & 0 & 16 & Wd-b $\times$ Gr-a & 0 & 48 & 3 \\
Gr-a $\times$ He-a & 59 & 0 & 58 & He-a $\times$ Gr-a & 0 & 64 & 53
\end{tabular}

\section{TABLE 4}

Reciprocal backcross $(B C)$ series. The original crosses are also shown in table 3. For legends see table 3

\begin{tabular}{clcccr} 
Cross & Generation & No. of crosses & \multicolumn{3}{c}{ No. of offspring } \\
& & & MS1 + IN1 & MS2 + IN2 & H \\
Gr-a $\times \mathrm{He}-\mathrm{a}$ & P & 1 & 59 & 0 & 58 \\
$\mathrm{MS} 1 \times \mathrm{He}-\mathrm{a}$ & BC1 & 2 & 241 & 0 & 47 \\
& BC2 & 2 & 95 & 0 & 8 \\
$\mathrm{BC} 3$ & BC3 & 3 & 140 & 0 & 51 \\
$\mathrm{H}$ Gr-a & P & 1 & 0 & 64 & 53 \\
$\mathrm{MS} 2 \times \mathrm{Gr}-\mathrm{a}$ & BC1 & 2 & 0 & 135 & 50 \\
& BC2 & 2 & 0 & 105 & 3 \\
& BC3 & 3 & 0 & 179 & 15
\end{tabular}

shown in table 4. Maternal inheritance of morphological type persisted during these three generations.

On the basis of the three experiments described above we distinguish two plasmon types, which will respectively be designated $R$ (Reduced stamens) in the case of type 1 sterility and P (Petaloid stamens) in the case of type 2 . When a plant is male sterile or intermediate its stamen morphology depends only on plasmon type. In hermaphrodites no distinction can be made between plasmon types on the basis of stamen morphology.

\section{(iii) Distribution}

The two morphs of male sterility are the expression of two different plasmon types. This provides us with a morphological marker for plasmon type by which it is comparatively easy to track local polymorphisms. Whenever the two male sterility types are found together in any population there apparently exists a polymorphism for plasmon type. Because hermaphrodites cannot be scored on the basis of their morphology, polymorphism can only be established by this method in a qualitative sense.

The results of the field counts are summarised in table 5. Frequencies of the five sex phenotypes are given together with sample size. Most of the 27 populations were scored once, either in 1980 or in 1981 but two populations, $\mathrm{Br}$ and $\mathrm{He}$, were examined in both years. In neither population did counts differ between years: $\chi^{2}(3)=1.90$ for $\mathrm{Br}$ and $\chi^{2}(3)=2.84$ for $\mathrm{He}$ (the figures for MS2 and IN2 were put together, see table 5). This is 
TABLE 5

Percentages of five sex phenotypes in natural populations. The populations are grouped according to habitat type (see text). At the sites $\mathrm{Me}, \mathrm{Bm}$ and Ac two populations were sampled

\begin{tabular}{|c|c|c|c|c|c|c|}
\hline Population & MS1 & IN1 & MS2 & IN2 & $\mathrm{H}$ & Sample size \\
\hline \multicolumn{7}{|l|}{ Hayfield I } \\
\hline $\mathrm{Dr}$ & 0 & 0 & $0 \cdot 2$ & 0.2 & $99 \cdot 6$ & 811 \\
\hline $\mathrm{Ze}$ & 0 & 0 & $5 \cdot 1$ & 0.8 & $94 \cdot 1$ & 742 \\
\hline An & 0 & 0 & $8 \cdot 2$ & $1 \cdot 3$ & $90 \cdot 5$ & 754 \\
\hline $\mathrm{Re}$ & 0 & 0 & $5 \cdot 0$ & $3 \cdot 6$ & 91.4 & 695 \\
\hline Me1 & 0 & 0 & 3.9 & $5 \cdot 5$ & $90 \cdot 6$ & 688 \\
\hline $\mathrm{Ve}$ & $12 \cdot 2$ & $2 \cdot 2$ & 0 & 0.6 & $85 \cdot 0$ & 623 \\
\hline $\mathrm{Br}$ & $23 \cdot 0$ & $7 \cdot 0$ & $0 \cdot 3$ & $0 \cdot 2$ & $69 \cdot 5$ & 601 \\
\hline \multicolumn{7}{|l|}{ Hayfield II } \\
\hline $\mathrm{Lu}$ & $3 \cdot 6$ & 0 & $2 \cdot 6$ & $1 \cdot 0$ & $92 \cdot 8$ & 194 \\
\hline $\mathrm{Ha}$ & $2 \cdot 7$ & 1.8 & $1 \cdot 8$ & $3 \cdot 6$ & $90 \cdot 1$ & 111 \\
\hline $\mathrm{Bm} 1$ & $7 \cdot 7$ & $11 \cdot 0$ & 0.4 & $1 \cdot 1$ & $79 \cdot 8$ & 273 \\
\hline $\mathrm{He}$ & $22 \cdot 0$ & $7 \cdot 4$ & 0.2 & 0.5 & $69 \cdot 9$ & 879 \\
\hline Ac1 & $13 \cdot 1$ & $19 \cdot 8$ & 0.2 & 0.6 & $66 \cdot 3$ & 535 \\
\hline \multicolumn{7}{|l|}{ Pasture } \\
\hline Wd & $4 \cdot 6$ & 0.6 & 0.5 & 0.9 & $93 \cdot 4$ & 6902 \\
\hline $\mathrm{Bm} 2$ & $7 \cdot 3$ & 3.9 & 0 & $1 \cdot 3$ & $87 \cdot 5$ & 386 \\
\hline $\mathrm{Pa}$ & 7.6 & $7 \cdot 8$ & 0.5 & 0.9 & $83 \cdot 2$ & 437 \\
\hline Ac2 & $11 \cdot 8$ & $10 \cdot 8$ & 0 & $1 \cdot 0$ & $76 \cdot 4$ & 305 \\
\hline $\mathrm{Ju}$ & $21 \cdot 5$ & $7 \cdot 0$ & 0 & 0.5 & $71 \cdot 0$ & 414 \\
\hline \multicolumn{7}{|l|}{ Verge } \\
\hline Vo & 2.9 & 1.5 & $1 \cdot 5$ & $3 \cdot 1$ & $91 \cdot 0$ & 547 \\
\hline $\mathrm{Sc}$ & $4 \cdot 5$ & 0.7 & $9 \cdot 6$ & $6 \cdot 9$ & $78 \cdot 3$ & 488 \\
\hline Wa & $11 \cdot 2$ & 0.4 & 1.4 & 4.7 & $82 \cdot 3$ & 278 \\
\hline $\mathrm{Lx}$ & $10 \cdot 1$ & $5 \cdot 8$ & 1.4 & 1.9 & $80 \cdot 8$ & 208 \\
\hline $\mathrm{Bd}$ & $15 \cdot 8$ & $7 \cdot 8$ & $0 \cdot 3$ & $0 \cdot 3$ & $75 \cdot 8$ & 373 \\
\hline \multicolumn{7}{|l|}{ Miscellaneous } \\
\hline $\mathrm{Te}$ & $3 \cdot 5$ & $2 \cdot 2$ & $0 \cdot 3$ & 1.9 & $92 \cdot 1$ & 630 \\
\hline $\mathrm{Gr}$ & 8.6 & 0.9 & $5 \cdot 5$ & $1 \cdot 8$ & $83 \cdot 2$ & 454 \\
\hline $\mathrm{Me} 2$ & $7 \cdot 6$ & $3 \cdot 5$ & $1 \cdot 8$ & $1 \cdot 2$ & 85.9 & 171 \\
\hline We & $7 \cdot 2$ & $6 \cdot 0$ & 0.7 & 0.9 & $85 \cdot 2$ & 554 \\
\hline Wv & $13 \cdot 1$ & $1 \cdot 0$ & $1 \cdot 5$ & $1 \cdot 5$ & 82.9 & 198 \\
\hline average & $8 \cdot 2$ & $4 \cdot 0$ & $2 \cdot 0$ & $1 \cdot 8$ & $84 \cdot 0$ & \\
\hline
\end{tabular}

not surprising because Plantago lanceolata is a true perennial in The Netherlands (cf. Krohne et al., 1980). The populations in table 5 are divided into three groups of different management: hayfields, pastures (extensively grazed by cattle and/or horses) and verges (comprising road and watersides). The hayfields are subdivided. In addition there is a miscellaneous group of populations $e . g$., at the Me site there is a copse of poplars (Me2), adjacent to the hayfield (Me1). We shall first consider the distribution of sex phenotypes and then consider it in relation to other population characteristics. made:

Taking all populations into account the following observations can be

- Hermaphrodites are always predominant. A population consists of at least two thirds of this phenotype.

- Averaged over all populations, intermediates are not rare compared to male steriles. IN1 reaches half the frequency of MS1 and the IN2 frequency almost equals that of MS2. Male steriles and intermediates 
are positively correlated $(r=0.43, P<0.05$, for type 1 and $r=0.58$, $P<0 \cdot 001$, for type 2 ).

- Type 1 steriles reach higher frequencies than type 2 steriles. The highest frequency of MS1 is 23 per cent, while MS2 always remains below 10 per cent. For intermediates the figures are similar. This is also seen in fig. 2 where frequencies of plants that express different plasmon types are plotted against each other.

- Fig. 2 also shows a negative correlation between the two sterility types $(r=-0 \cdot 58, P<0 \cdot 001)$. At high frequencies of type 1 sterility the frequencies of type 2 are all close to zero. When type 1 frequency decreases, not only the mean of type 2 frequency rises but also the variation around it.

- It appears from both table 5 and fig. 2 that 22 out of 27 populations contain both sterility types. In all cases the shortest distance between a MS1 and a MS2 plant was within a few meters. Although male sterile frequencies are sometimes low, these data show that in 80 per cent of the populations studied both plasmon types occur in close proximity to each other.

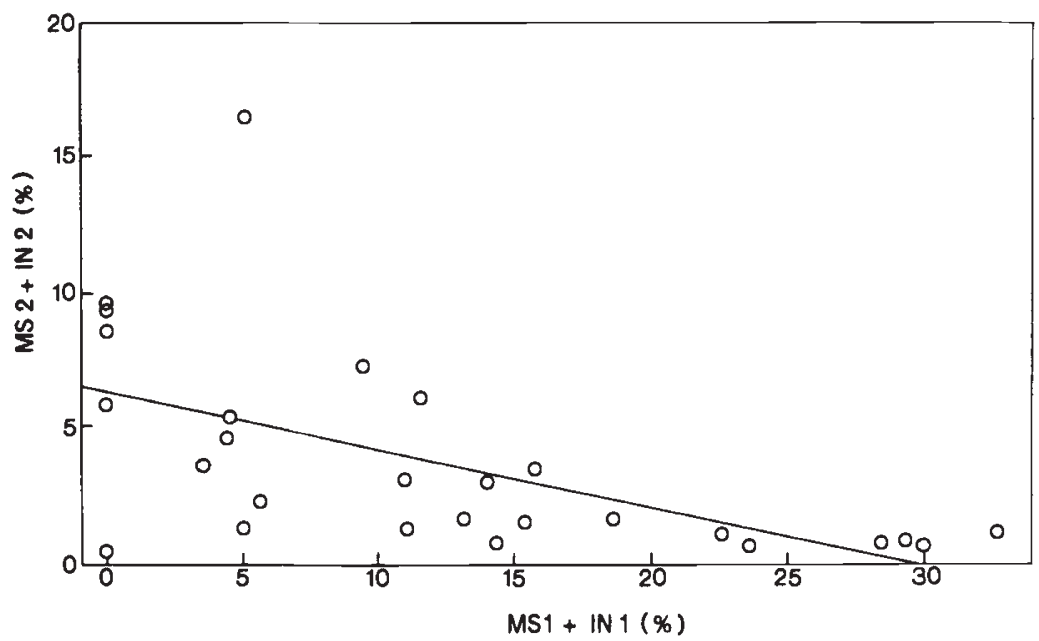

FIG. 2.-Relationship between frequency of type 1 steriles (MS1 + IN1) and frequency of type 2 steriles (MS2 + IN2) in natural populations of Plantago lanceolata.

The last observation is of particular interest because it shows that the polymorphism for plasmon type is widespread. The figure of 80 per cent is possibly an underestimate. Absence of MS1 and IN1 does not necessarily mean absence of plasmon $R$. It can still be present in hermaphrodites which constitute over 90 per cent of the five populations concerned. An indication, however, that these populations may be fixed for plasmon $\mathrm{P}$ comes from the Me site. The hayfield $\mathrm{Me} 1$ contains a large population of Plantago lanceolata. The hayfield is isolated except that it is adjacent to a copse of poplars with a small plantain population (a few hundred flowering individuals). This population contains 3 per cent type 2 steriles and 11 per cent type 1 steriles while the latter are absent in the hayfield (table 5). In the first $10 \mathrm{~m}$ of the hayfield adjacent to the copse in 1979 a few type 1 
steriles were found. Seeds collected from a sample of 244 of these plants gave 57 per cent MS1 and 16 per cent IN1, the rest being hermaphrodite. However, in later years type 1 steriles were not found again in the ten meter zone and a seed sample collected from hermaphrodites in the hayfield, revealed no type 1 sterile among 181 offspring. This suggests that plasmon $R$ has not spread through the hayfield although migration from the copse occurs at least occasionally.

In table 5 the populations are grouped according to three ways of management with an additional miscellaneous group. Subdivision of the hayfield group is based on vegetational characteristics. The populations of hayfield I are predominantly occupied by vegetations from the alliances Calthion palustris and Junco-Molinion, which are hardly represented in the other hayfields or in any other population in table 5. In addition all populations, except three from the miscellaneous group, were characterised for several soil parameters: moisture-, organic matter-, nitrogen- and phosphorus content and $p \mathrm{H}$. In table 6 the ranges of these parameters are given for the habitat types. The hayfield I group is quite different from the other groups which in turn show considerable overlap for all five parameters. The populations from hayfield I tend towards a lower $p H$, higher phosphorus content and score distinctly higher, without any overlap, in moisture, organic matter and nitrogen content. This group is characterised by very wet, peaty soils and vulnerable vegetation types.

Returning to table 5 , type 2 sterility shows little divergence between habitats. The frequencies in the pasture group seem lower than average but low values also occur in other groups. Correlations of type 2 sterile frequency and environmental variables from table 6 were all non-significant.

For type 1 sterility the situation is different: the five populations presumably fixed for plasmon $\mathrm{P}$, all belong to the hayfield I group. As might be anticipated from the difference between this group and others in table 6 , the frequency of type 1 steriles and the soil parameters moisture-, organic matter- and nitrogen content are negatively correlated $(r=-0.44,-0.44$ and -0.42 , all with $P<0.05$ ). Correlations with phosphorus content and $\mathrm{pH}$ are not significant. By leaving out selectively these five populations from calculations, the range of frequencies is little affected but all correlations disappear. The populations that lack type 1 sterility are apparently not randomly distributed over the various habitat types that were included in this study. Another indication that the distribution of type 1 sex phenotypes may depend on environmental conditions comes from the two sites Ac and $\mathrm{Bm}$. At both sites a mown and a grazed field were scored simultaneously (table 5). The fields are respectively adjacent and $100 \mathrm{~m}$ distant from each other and at each site they are very similar in soil parameters. A chi-square analysis of the distribution data shows significant differences: $\chi^{2}(3)=12.67(P<0.01)$ for Ac and $\chi^{2}(3)=13.02(P<0.01)$ for $\mathrm{Bm}$ (the figures for MS2 and IN2 were put together). In both cases the difference is due to the higher frequency of IN1 in the mown section at the expense of $\mathrm{H}$ plants.

\section{DisCUSSION}

In this paper evidence is presented for the existence of two plasmon types in Plantago lanceolata. Polymorphism for plasmon type appears to 


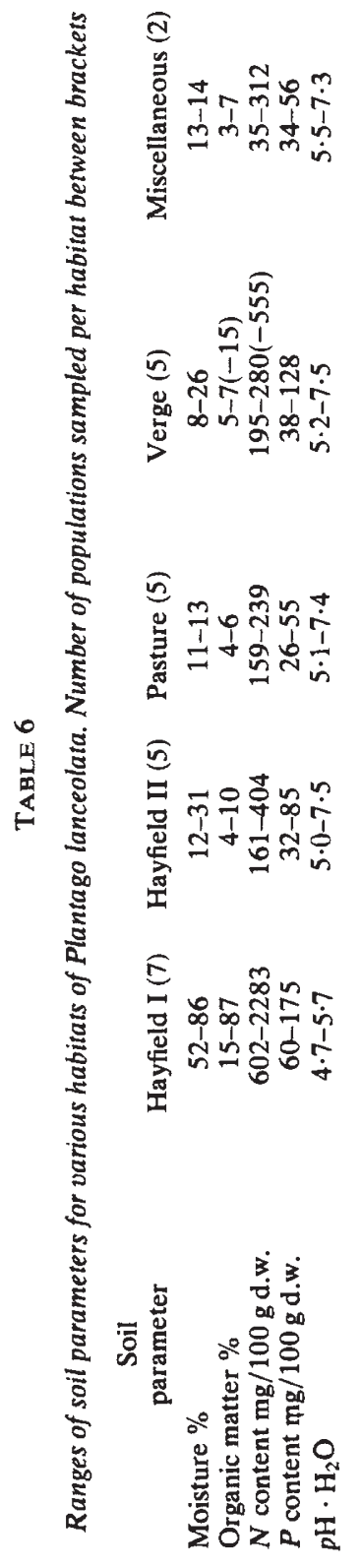


be common: it was found in 22 out of 27 populations. This result is based entirely on cytoplasmic determination of male sterile morphology which thereby served as a marker for plasmon type. Such a relation is not uncommon. Male sterility genes, whether localised in the nucleus or in the cytoplasm, often interfere with normal stamen development in specific stages. For example in Zea mays and Lycopersicon esculentum, numerous non-allelic nuclear male sterility genes are known which can be distinguished from each other by cytological and histological observations (Gottschalk and Kaul, 1974). But differences in the timing of breakdown of stamen development are often reflected in male sterile morphology. Frankel and Galun (1977) summarize the variety of possible male sterile phenotypes in angiosperms. Male sterile morphs as we found for Plantago lanceolata are common: petaloid transformation of stamens is found in many species (Meyer, 1966), as is reduction of corolla size (Lloyd and Webb, 1977). A species with similar properties to Plantago lanceolata, is Daucus carota. It has a petaloid and a reduced stamen type of male sterility both of which have been collected from the wild (but from different populations) and male sterile morphology is cytoplasmically determined (Morelock, 1974). Other examples come from Knautia arvensis (Correns, 1906), Allium cepa (Jones and Emsweller, 1936; van der Meer, 1976) and from interspecies crosses in Nicotiana (Chaplin, 1964), Gossypium (Meyer and Meyer, 1961) and Brassica (Pearson, 1972).

Variation in sex expression in Plantago lanceolata has been reported for more than a century by at least 17 different authors. Earlier researchers especially gave very detailed descriptions of individual sex phenotypes. However, partition of the variation in male sterile expression into two groups, as in this paper, has not been done previously. Nevertheless from those descriptions it can be inferred that both plasmon types were present long ago in England (Coleman, 1876; Darwin, 1877; Turrill, 1919; HopeSimpson, 1939), in Germany (Ludwig, 1879; Schulz, 1888; Correns, 1908) and in the United States (Bartlett, 1911; Stout, 1919). Correns (1906), in fact, was the first to report a polymorphic population, without however being aware of it. He states that the seeds he used for his crossing experiments, were collected from a single roadside near Leipzig. From descriptions of individual plants in this and a subsequent paper, it appears that the population contained both sterility types (Correns, 1906, 1908). These descriptions support our finding that polymorphism for plasmon type is widespread.

More recent authors on male sterility in Plantago lanceolata paid little or no attention to male sterile morphology (Ross, 1967, 1969; Primack, 1978; Krohne et al., 1980). From personal communications with all three authors it appeared that they have been working with MS1, if not with both types. In contrast to most earlier authors, however, they gave estimates of proportions of male sterile plants in a total of 43 populations. Assuming that their counts include both male sterility types, the results agree very well with ours, as presented in table 5 . The frequencies of male sterile plants range from zero to one third, the majority being less than one quarter. Rough estimates by earlier authors indicate the same range (Schulz, 1888; Blaringhem, 1923). The only exception is an unspecified figure of 0.70 from Baker (1963). Frequencies of intermediates have not been established before. It appears from the present study (table 5) that the 
frequency range of each type of intermediate almost equals that of the corresponding male steriles. For virtually all gynodioecious species intermediates have been reported, but only rarely have they been studied. A study of the genetics and reproductive characteristics of intermediate plants would be of interest as they might be involved in the maintenance of male sterility (cf. Charlesworth and Charlesworth, 1978b).

We are not aware of other reports on an extensive plasmon polymorphism within populations of a gynodioecious species. An elaborate study was made by Kheyr-Pour $(1980,1981)$ on male sterility in Origanum vulgare. He obtained differences between reciprocal crosses and distinguished three different plasmon types. These plasmon types (V, P and Y) originally came from different populations, but no definite conclusions can be drawn from his comparison of plasmon types from the same population. One of the reasons that so few joint polymorphisms are known, is the cumbersome procedure needed to identify a new plasmon source. A deviant plasmon type is usually indicated by differences in segregation ratios between reciprocal crosses that persist during a number of generations (Grun, 1976). Screening even a medium-sized population by this method is made virtually impossible by the amount of work needed. Research was greatly facilitated in Plantago lanceolata because plasmon type is expressed in flower morphology in male steriles and intermediates, which can be judged by eye. Yet the conclusions are only qualitative because plasmon type is expressed only in non-hermaphrodite plants. Male sterile frequencies within each plasmon type cannot be determined. This makes an interpretation of the negative correlation in figure 2 difficult. The correlation can be a consequence of varying plasmon frequencies or of male sterile frequencies varying within each plasmon type or of a combination of both. Accurate estimates of plasmon frequencies cannot be obtained until a means has been found to discriminate between $\mathrm{H} 1$ and $\mathrm{H} 2$ plants, otherwise than by the laborious way of growing their progeny. Such relatively simple test methods, allowing rapid screening of individuals, have been developed for several agricultural species, like Zea mays (Kemble, 1980; Kemble et al., 1980) and Beta vulgaris (Georgescu et al., 1979), where reproducible differences between plasmon types have been found in protein- and DNAelectrophoresis pattern and in enzyme activity respectively.

Inheritance of male sterility in Plantago lanceolata is known to be complex (Correns, 1908). Ross (1969) proposed a digenic system which was based on one plasmon source, probably plasmon $\mathbf{R}$. It was shown in this paper that the cytoplasm is involved in the inheritance of male sterility. Most of the genetic data in tables 2, 3 and 4 are presented as summations of crosses and, consequently, an exact interpretation of the ratios is not possible. Yet it is clear that nuclear genes are also involved, as both male sterility types are capable of segregating hermaphrodites on the one hand and of being segregated by hermaphrodites on the other. In a following paper it will be shown in detail that each male sterility type has nuclearcytoplasmic inheritance. No evidence has been found for a third plasmon type. All plants tested could be classified by their progeny as having either the one or the other plasmon type. Simple models did not fit the results. For each sterility type a number of interacting nuclear genes is involved. Those responsible for the MS1 phenotype when cooperating with plasmon $\mathrm{R}$, appeared to result in the hermaphroditic phenotype with plasmon $\mathrm{P}$. 
The reverse holds for MS2 (van Damme, in prep.). Even without a knowledge of the number and nature of the nuclear genes it is easy to see that the low average frequencies of hermaphrodites occurring in most crosses. between plants with different plasmon types in tables 2,3 and 4 can in principle be explained with this system.

The plasmon polymorphism, described in this paper, makes it likely that nuclear-cytoplasmic inheritance not only holds for the species but also for populations (joint polymorphism). Plantago lanceolata can be regarded as a stable gynodioecious species (sensu Ross, 1978). Conditions for the maintenance of male steriles in this type of gynodioecy have only been studied to a limited extent. Charlesworth (1981) has shown that under certain conditions a stable joint polymorphism can be obtained in a selfincompatible species like Plantago lanceolata. One of the assumptions of the model is that male sterility genes have associated fitness effects. Experiments are in progress on fitness determining characteristics as a function of sex in order to explain the extensive joint polymorphism in Plantago lanceolata (van Damme, in prep.). The situation however, is more complex than any of the models published hitherto: there are two male sterility types, which do not contribute equally to the total frequency of male sterile plants. On the whole the frequency of MS1 is higher than that of MS2. One might expect to find corresponding differences in fitness determining characteristics, but it is not known to what extent the two male sterility types are determined by different nuclear genes and what implications an eventual gene, common to both male sterility types, has for the maintenance of the system.

Another complication may be that fitness values depend on environment. Some evidence in favour is presented in this paper, but it should be interpreted with some caution. For instance, the differences in IN1 and H frequencies between mown and grazed fields at the Ac and Bm site might simply be due to environmentally dependent sex expression. The finding stresses the importance of involving intermediates in the study of the maintenance of male steriles in natural populations. Type 1 steriles (and possibly plasmon $\mathrm{R}$ ) were absent in five populations. All these populations belong to one particular habitat type. The three soil parameters that are negatively correlated with the frequency of type 1 steriles are highly interrelated and are merely meant to support the separation of the hayfield I group on the basis of vegetation type. The chance that the five populations, occurring at random, are all found in the hayfield I group can be calculated. It is as low as 0.00026 . Correlations between the frequency of male steriles and environmental variables have been found before in Plantago lanceolata by Blaringhem (1923) and Krohne et al. (1980). Since it is not clear whether these authors have been working solely with MS1 or with both types, comparison with our results is not possible. Krohne et al. (1980) found a positive correlation between male sterile frequency and percentage soil moisture, but there is no overlap in moisture measurements with ours, their highest value being 6 per cent (cf. table 6 ). We apparently have been working in a different series of environments. Similar correlations have been found in two other gynodioecious species: Silene vulgaris (Brockmann and Bocquet, 1978) and Thymus vulgaris (Dommée et al., 1978). In both cases it was argued that selection is responsible for the observed distribution of sexes and that fitness values of the sexes depend on environmental 
conditions. We think that the correlation found in Plantago lanceolata deserves further attention.

Acknowledgements,-We wish to thank Drs R. Bijlsma, D. Charlesworth, G. van Nigtevecht and J. Woldendorp for their comments on the manuscript, and S. Troelstra and coworkers for performing soil analyses. Fig. 1 was drawn by E. Leeuwinga. These investigations were supported by the Foundation for Fundamental Biological Research (BION), which is subsidized by the Netherlands Organization for the Advancement of Pure Research (ZWO).

\section{REFERENCES}

ALEXANDER, M. P. 1969, Differential staining of aborted and nonaborted pollen. Stain Techn., 44, 117-122.

ARROYO, M. T. K., AND RAVEN, P. H. 1975. The evolution of subdioecy in morphologically gynodioecious species of Fuchsia sect. Encliandra (Onagraceae). Evolution, 29, 500-511. BAKER, H. G. 1963. Evolutionary mechanisms in pollination biology. Science, 139, 877-883. BARTLETT, H. H. 1911. On gynodioecism in Plantago lanceolata. Rhodora, 13, 199-206.

BLARINGHEM, L. 1923. Etudes sur le polymorphisme floral. IV. Sexualité et métamorphose des épis de Plantago lanceolata L. Bull. Soc. botan. France, 70, 717-725.

BROCKMANN, I., AND BOCQUET, G. 1978. Ökologische Einflüsse auf die Geschlechtsverteilung vei Silene vulgaris (Moench) Garcke (Caryophyllaceae). Ber. Deutsch. Bot. Ges., 91, 217-230.

CASPARI, E., WATSON, G. S., AND SMITH, w. 1966. The influence of cytoplasmic pollen sterility on gene exchange between populations. Genetics, 53, 741-746.

CHAPLIN, J. F. 1964. Use of male sterile tobacco in the production of hybrid seed. Tobacco Sci., 8, 105-109.

CHARLESWORTH, B., AND CHARLESWORTH, D. 1978 a. A model for the evolution of dioecy and gynodioecy. Amer. Nat., 112, 975-997.

CHARLESWORTH, D. 1981. A further study of the problem of the maintenance of females in gynodioecious species. Heredity, 46, 27-39.

CHARLESWORTH, D., AND CHARLESWORTH, B.1978b. Population genetics of partial malesterility and the evolution of monoecy and dioecy. Heredity, 41, 137-153.

CHARLESWORTH, D., AND GANDERS, F. R. 1979. The population genetics of gynodioecy with cytoplasmic-genic male-sterility. Heredity, 43, 213-218.

COlEMAN, N. 1876. Plantago lanceolata L. Bot. Bull., 1, 45.

CONNOR, H. E. 1973. Breeding systems in Cortaderia (Gramineae). Evolution, 27, 663-678.

CORRENS. C. Die Vererbung der Geschlechtsformen bei den gynodiöcischen Pfianzen. Ber. Deutsch. Bot. Ges., 24, 459-474.

CORRENS, C. 1908. Die Rolle der männlichen Keimzellen bei der Geschlechtsbestimmung der gynodioecischen Pflanzen. Ber. Deutsch. Bot. Ges., 26a, 686-701.

COSTATINO, R. F. 1971. Genetic consequences of the couplet cytoplasmic pollen sterility and pollen migration. Genetics, 68, 313-321.

DARWIN, C. 1877. Different Forms of Flowers on Plants of the Same Species. John Murray, London.

DELANNAY, X., GOUYON, P. H., AND VALDEYRON, G. 1981. Mathematical study of the evolution of gynodioecy with cytoplasmic inheritance under the effect of a nuclear restorer gene. Genetics, 99, 169-181.

DOMMEE, B., ASSOUAD, M. W., AND VALDEYRON, G. 1978. Natural selection and gynodioecy in Thymus vulgaris L. Bot. J. Linn. Soc., 77, 17-28.

EDWARDSON, J. R. 1970. Cytoplasmic male sterility. Bot. Rev., 36, 341-420.

FRANKel, R., AND GALUN, E. 1977. Pollination Mechanisms, Reproduction and Plant Breeding. Monographs on Theoretical and Applied Genetics 2, Springer-Verlag, Berlin.

GANDERS, F. R. 1978. The genetics and evolution of gynodioecy in Nemophila menziesii (Hydrophyllaceae), Can. J. Bot., 56, 1400-1408.

GeORGESCU, C. M., RÖMER, D., AND OLTEANU, $G^{\text {h }}$. 1979. Peroxidase activity as a possible test for distinguishing S-plasm from N-plasm in sugar beet (Beta vulgaris L.). Euphytica, 28, 779-784.

GOTTSCHALK, W., AND KAUL, M. L. H. 1974. The genetic control of microsporogenesis in higher plants. Nucleus (Calcutta), 17, 133-166.

GRUN, P. 1976. Cytoplasmic Genetics and Evolution. Columbia Univ. Press, New York. 
HOPE-SIMPSON, J. F. 1939. Reduction of the androecium in Plantago lanceolata L. J. Bot., 77, 290-293.

Jones, H. A., AND EMSWeller, S. L. 1936. A male-sterile onion. Proc. Am. Soc. hort. Sci., $34,582-585$.

KEMBLE, R. J. 1980. A rapid, single leaf assay for detecting the presence of "S"-male-sterile cytoplasm in maize. Theor. Appl. Genet., 57, 97-100.

KEMBLE, R. J., GUNN, R. E., AND FLAVELL, R. B. 1980. Classification of normal and male-sterile cytoplasms in maize. II. Electrophoretic analysis of DNA species in mitochondria. Genetics, 95, 451-458.

KHEYR-POUR, A. 1980. Nucleo-cytoplasmic polymorphism for male sterility in Origanum vulgare L. J. Hered., 71, 253-260.

KHEYR-POUR, A. 1981. Wide nucleo-cytoplasmic polymorphism for male sterility in Origanum vulgare L. J. Hered., 72, 45-51.

KROHNE, D. T., BAKER, I., AND BAKER, H. G. 1980. The maintenance of the gynodioecious breeding system in Plantago lanceolata L. Amer. Midl. Natur., 103, 269-279.

LEWIS, D. 1941. Male sterility in natural populations of hermaphrodite plants. New Phytol, $40,56-63$.

LLOYD, D. G., AND WEBB, C. J. 1977. Secondary sex characters in seed plants. Bot. Rev., $43,177-216$.

LUDWIG, F. 1879. Ueber die Blütenformen von Plantago lanceolata L. und die Erscheinung der Gynodiöcie. Z. ges. Naturwiss., 52, 441-449.

MEYER, J. R., AND MEYER, N. G. 1961. Cytoplasmic male sterility in cotton. Genetics, 46, 883.

MEYER, V. G. 1966. Flower abnormalities. Bot. Rev., 32, 165-218.

MORELOCK, T. E. 1974. Influence of Cytoplasmic Source on Expression of Male Sterility in Carrot, D. carota. Ph.D. Thesis, Univ. of Wisconsin.

PRIMACK, R. B. 1978. Evolutionary aspects of wind pollination in the genus Plantago (Plantaginaceae). New Phytol., 81, 449-458.

PEARSON, O. H. 1972. Cytoplasmically inherited male sterility characters and flavor components from the species cross Brassica nigra (L.) Koch $\times$ B. oleracea L. J. Am. Soc. Hort. Sci., 97, 397-402.

ROSS, M. D. 1967. Two genetic mechanisms governing outbreeding in Plantago lanceolata. Genetics, 56, 584-585.

ROSS, M. D. 1969. Digenic inheritance of male sterility in Plantago lanceolata. Can. J. Genet. Cytol., 11, 739-744.

ROss, M. D. 1973. Inheritance of self-incompatibility in Plantago lanceolata. Heredity, 30, $169-176$.

ROSs, M. D. 1978. The evolution of gynodioecy and subdioecy. Evolution, 32, 174-188.

ROSS, M. D.. AND WEIR, B. S. 1976. Maintenance of males and females in hermaphrodite populations and the evolution of dioecy. Evolution, 30, 425-441.

SCHULZ, A. 1888. Beitäage zur Kenntnis der Bestäubungseinrichtungen und Geschlechtsverteilung bei den Pflanzen. Bibl. Botan., 10,90-93.

STOUT, A. B. 1919. Intersexes in Plantago lanceolata. Bot. Gaz., 68, 109-133.

TROELSTRA, S. R., SLUIMER, L., SMANT, W., WAGENAAR, R., AND VAN DER MEULEN, M. A. 1981. On the soil chemistry of natural habitats of Plantago species and Hypochaeris radicata in various parts of the Netherlands in relation to the chemical composition of the plants. Verh. Kon. Ned. Acad. Wetensch., Afd. Natuurk. $2^{e}$ Reeks, 77, Progress Report 1980 I.O.O., 20-32.

TURRILL, W. B. 1919. Female flowers in Plantago lanceolata. J. Bot., 57, 196.

VALDEYRON, G., ASSOUAD, W., AND DOMMEE, B. 1970. Coexistance des déterminismes genique et cytoplasmique de la sterilité male. In La Sterilité Male Chez les Plantes Horticoles. Eucarpia meeting Versailles, 175-186.

VAN DER MEER, Q. P. 1977. Ui. IVT Annual Report 1976, 25-27.

WATSON, G. S., AND CASPARI, E. 1960. The behaviour of cytoplasmic pollen sterility in populations. Evolution, 14, 56-63.

WEBB, C. J. 1979. Breeding systems and the evolution of dioecy in New Zealand apioid Umbelliferae. Evolution, 33, 662-672. 